\title{
Influence of carbon content on the microstructure, mechanical and tribological properties of CrAICN coatings deposited by DC unbalanced magnetron sputtering
}

\author{
ELBERT CONTRERAS ROMERO ${ }^{1}$, MARYORY GÓMEZ BOTERO ${ }^{1}$, WOLFGANG TILLMANN ${ }^{2}$, \\ FRANCISCO BOLÍVAR OSORIO ${ }^{1}$ and GILBERTO BEJARANO GAITÁN ${ }^{1, * \mathbb{D}}$ \\ ${ }^{1}$ Centro de Investigación, Innovación y Desarrollo de Materiales - CIDEMAT, Universidad de Antioquia, Calle 70 No. \\ 52-21, Medellín, Colombia \\ ${ }^{2}$ Institute of Materials Engineering, Technische Universität Dortmund, 44227 Dortmund, Germany \\ *Author for correspondence (gilberto.bejarano@udea.edu.co)
}

MS received 25 January 2017; accepted 17 November 2017; published online 18 July 2018

\begin{abstract}
The influence of carbon content on the microstructure, mechanical and tribological properties of $\mathrm{CrAlCN}$ was systematically investigated. For this purpose, five duplex coatings of CrAlCN deposited on AISI H13 steel by the magnetron-sputtering technique were developed. The carbon content of the coatings was varied between 10.26 and 80.56 at $\%$ by modifying the percentage of methane in the working gas mixture $\mathrm{CH}_{4} /\left(\mathrm{Ar}+\mathrm{N}_{2}\right)$. The effect of carbon content on the morphology, microstructure, mechanical and tribological properties of the $\mathrm{CrAlCN}$ coatings was evaluated. Coatings showed a high crystalline structure at low carbon contents, consisting mainly of chromium nitrides and aluminium-chromium nitrides. With the increase of carbon content in the coatings, chromium carbides formed at the expense of nitrides, presenting a highly amorphous structure with high carbon content. Initially, the hardness and Young's modulus of the coatings increased with carbon content, possibly due to hardening of the interstitial solid solution of carbon within the matrix of CrAlN. Then, they were decreased along with the coefficient of friction and wear rate due to the self-lubricating effect of graphite-like carbon. However, above the 54.74 at\% carbon, the wear rate of $\mathrm{CrAlCN}$ increased again, probably due to the low hardness and adhesion of the coating. The CrAlCN coating with a carbon content of 21.96 at $\%$ presented the best balance between mechanical and tribological properties.
\end{abstract}

Keywords. Quaternary coatings; magnetron sputtering; aluminium-chromium-carbonitride; tribology; hard coatings; anti-wear coatings.

\section{Introduction}

The need to modify the surface of materials to increase its performance has had a great evolution in recent decades. Currently, the deposition of hard coatings was one of the most commonly used methods for improving mechanical and tribological properties of materials. For many years, binary coatings, such as $\mathrm{TiN}, \mathrm{CrN}, \mathrm{ZrN}$ were proved to be the best solutions due to the good thermal, mechanical and tribological properties conferred on the parts and tools coated with these materials [1-6]. However, the inclusion of modern technologies and improved production processes have led to a growing demand for new materials with improved properties, as well as to the research and development of new coatings. One way to improve the properties of the coatings was the incorporation of new elements, forming ternary and quaternary coatings with improved hardness, coefficient of friction, wear rate, and thermal and chemical stabilities, among other advantages. The incorporation of new elements into the crystal lattices of the coatings causes changes in the structure, such as the formation of solid solutions, intermediates or composite phases, which are responsible for improving the properties of the coatings [7-9]. For example, adding up to 75 at $\%$ of $\mathrm{Al}$ in the structure of $\mathrm{CrN}$ partially replaces the $\mathrm{Cr}$ occupying the vacancies of the matrix to form the ternary coating of $\mathrm{Cr}_{1-x} \mathrm{Al}_{x} \mathrm{~N}$ with a cubic NaCl-type structure. The improved properties of the latter coating are associated with aluminium content. When this aluminium content corresponding to the solubility limit of $\mathrm{Al}$ in the $\mathrm{CrN}$ is exceeded, composite structures of cubic and hexagonal wurtzite-type phases $(\mathrm{ZnS}(\mathrm{w}))$ or wurtzite-type structures alone are obtained [10-16]. The cubic structure in these coatings showed superior mechanical properties compared to the wurtzite type. In recent years, several authors have reported properties of ternary CrAlN coatings higher than $\mathrm{CrN}$ coatings with hardness between 30 and $40 \mathrm{GPa}$, friction coefficients between 0.6 and 0.7 and wear rates of the order of $10^{-16} \mathrm{~m}^{3} \mathrm{~nm}^{-1}[10,11]$. The properties exhibited by this ternary system make it a good candidate for tribological applications. Other quaternary alloys based on $\mathrm{CrN}$ coatings, like $\mathrm{Cr}-\mathrm{Mo}-\mathrm{C}-\mathrm{N}, \mathrm{Cr}-\mathrm{Si}-\mathrm{C}-\mathrm{N}, \mathrm{Cr}-\mathrm{Al}-\mathrm{Si}-\mathrm{N}, \mathrm{Cr}-$ $\mathrm{Mo}-\mathrm{Si}-\mathrm{N}$ and $\mathrm{Cr}-\mathrm{Al}-\mathrm{C}-\mathrm{N}$ [17-20] have shown improved 
Table 1. Some characteristics of deposited CrAlCN coatings.

\begin{tabular}{lcccccc}
\hline Coating & Carbon content (at\%) & Roughness, $R_{\mathrm{a}}(\mathrm{nm})$ & Grain size $(\mathrm{nm})$ & $\begin{array}{c}\text { Deposition rate } \\
\left(\mathrm{nm} \mathrm{h}^{-1}\right)\end{array}$ & Thickness $(\mathrm{nm})$ & $H^{3} / E^{2}$ ratio \\
\hline M1 & 10.26 & $96.66 \pm 4.43$ & $258 \pm 9.1$ & 576.67 & 1730 & 0.081 \\
M2 & 21.96 & $40.57 \pm 3.68$ & $279 \pm 10.7$ & 534.00 & 1602 & 0.095 \\
M3 & 38.53 & $64.53 \pm 2.67$ & $222 \pm 9.6$ & 450.00 & 1350 & 0.031 \\
M4 & 54.74 & $77.79 \pm 7.81$ & $239 \pm 8.2$ & 423.34 & 1270 & 0.016 \\
M5 & 80.56 & $79.37 \pm 2.46$ & $309 \pm 11.3$ & 340.67 & 1022 & 0.024 \\
\hline
\end{tabular}

mechanical and tribological properties. This is mainly due to grain refinement at nanoscale, precipitation hardening, formation of hard intermetallic and amorphous phases, lowering the coefficient of friction and increasing the toughness of the coatings $[9,12]$. In particular, study of the effect of addition of carbon to ternary coatings, including CrAlN, has gained great importance and it is a current trend in the development of hard coatings. This is because of the self-lubricating effect of this element, which improves the tribological properties and wear resistance of these coatings. However, the effect of carbon content on the microstructure and properties of CrAlCN coatings was not understood and not explained enough and it needs to be investigated further. There are few reports on the influence of carbon on the microstructure and mechanical and tribological properties of $\mathrm{CrAlCN}$. The more recent research works carried out, reported $\mathrm{CrAlCN}$ coatings deposited by hybrid methods, such as the combination of cathodic arc and DC magnetron-sputtering deposition techniques. Tillmann et al [19] deposited and characterized hard CrAlCN coatings using MF-magnetron sputtering and acetylene as reactive gas. However, the deposition parameters and properties of the coatings differ greatly according to the manufacturing technique used. In this paper, the influence of carbon content on the microstructure, mechanical and tribological properties of CrAlCN coatings deposited by DC unbalanced magnetron sputtering was determined. The carbon content in the coatings was controlled by varying the ratio of methane/nitrogen gas, and keeping the other process parameters constant.

\section{Experimental}

\subsection{Coatings deposition}

CrAlCN coatings were deposited in a vacuum chamber of $550 \times 600 \times 800 \mathrm{~mm}$ using the reactive unbalanced magnetronsputtering technique and a binary $\mathrm{Cr} / \mathrm{Al}$ target (99.9\% purity) with a composition of $70 / 30$ at $\%$ and dimensions of $500 \times$ $100 \times 6 \mathrm{~mm}$.

Cylindrical plates of AISI H13 steel with $2.54 \mathrm{~cm}$ diameter and $4.0 \mathrm{~mm}$ thickness were used as substrates. This steel is commonly used for the manufacture of moulds and dies for hot-forming processes of metallic products. The steel samples were polished using 220, 360, 400, 600, 800, 1000,
1200 and 1500 grit $\mathrm{SiC}$; and polished to a mirror finish with a $0.5 \mu \mathrm{m}$ alumina solution. Subsequently, samples were cleaned in an ultrasonic bath of ethanol (75\%) and acetone $(25 \%)$ for $20 \mathrm{~min}$. The deposition chamber was evacuated to a base pressure of $<5 \times 10^{-5}$ mbar. Before deposition, the target and substrates were cleaned inside the vacuum chamber by argon ion bombardment for $30 \mathrm{~min}$ at a pressure of $7 \times 10^{-2}$ mbar and substrate bias of $-650 \mathrm{~V}$. Prior to coating deposition, a pulsed plasma nitriding process was carried out for all steel substrates to increase their surface hardness and to improve the adhesion between the $\mathrm{CrAlCN}$ coating and the substrates. Plasma nitriding was carried out at $450^{\circ} \mathrm{C}$ and pressure of $7 \times 10^{-2}$ mbar for $6 \mathrm{~h}$ in a gas mixture of $\mathrm{Ar} / \mathrm{N}_{2} / \mathrm{H}_{2}$. All CrAlCN coatings were deposited for $3 \mathrm{~h}$ at a temperature of $310^{\circ} \mathrm{C}$, pressure of $7 \times 10^{-3} \mathrm{mbar}$, bias voltage of $-170 \mathrm{~V}$ and a power density of $2 \mathrm{~W} \mathrm{~cm}^{-2}$ applied to the $\mathrm{Cr} / \mathrm{Al}$ target. The carbon content in the coatings was adjusted by varying the flow of methane $\left(\mathrm{CH}_{4}\right)$ in the work gas mixture $\mathrm{CH}_{4} /\left(\mathrm{Ar}+\mathrm{N}_{2}\right)$ (purity $99.999 \%$ ) as shown in table 1 , and maintaining other process parameters as constants.

\subsection{Coatings characterization}

Phases composition and crystalline microstructure were established with an X-ray diffractometer (Panalytical Empyream) in the mode $\theta-2 \theta$, using $\mathrm{CuK} \alpha 1$ radiation of wavelength, $\lambda=1.540598 \AA, 45 \mathrm{kV}, 40 \mathrm{~mA}$, scan range $30^{\circ}-70^{\circ}$ and scan step of $0.02^{\circ} \mathrm{s}^{-1}$.

A complementary analysis of phase composition was carried out using a confocal high-resolution micro-Raman spectroscope (Horiba JobinYvon, Model Labram), equipped with a $\mathrm{He} / \mathrm{Ne}$ laser with wavelength of $633 \mathrm{~nm}$ and power of $17 \mathrm{~mW}$. This technique was also used to assess the wear track and debris resulting after the wear test.

The morphology and elemental chemical composition of the coatings were analysed by energy dispersive X-ray spectroscopy (EDS) in a JSM-6490LV SEM JEOL scanning electron microscope (SEM) equipped with a microprobe and supported with INCA energy software. The thickness of the coatings was determined using a Bruker contact profilometer model DektakXT. Both the roughness and grain size were measured in triplicate by a computer controlled Easyscan 2 Flex brand atomic force microscope (AFM) using a silicon nitride tip in contact mode. 
Hardness and Young's modulus measurements were conducted using an UBI1-Hysitron nanoindenter using a Berkovich diamond indenter tip (three-sided pyramid) with a maximum load of $400 \mathrm{mN}$ and an indentation depth of $150 \mathrm{~nm}$. Each specimen was tested using the continuous stiffness measurement mode (CSM) with a dynamic contact module (DCM). Forty-nine indentations were made on each coating to obtain appropriate statistical results. The indentation hardness $(H)$ and Young's modulus $(E)$ were calculated by nanoindenter software based on the model of Oliver and Pharr [21].

Tribological properties were determined in a ball on disctype tribometer using a sphere of alumina with $6 \mathrm{~mm}$ in diameter as counter-body. A rotation speed of $30 \mathrm{rpm}$ at an applied load of $4 \mathrm{~N}$ for $20 \mathrm{~min}$ and a track radius of $2 \mathrm{~mm}$ was used. The tribological tests were performed in ambient air at a temperature of $23 \pm 2{ }^{\circ} \mathrm{C}$ and relative humidity of $45 \pm 5 \%$.

Samples and counter bodies were cleaned and degreased before and after each test in an ultrasonic bath with $75 \%$ alcohol and 25\% acetone. In addition, they were weighed in a METTLER TOLEDO MX5 Microbalance before and after each test to determine the mass lost. To evaluate the wear mechanisms, wear tracks of all samples tested were observed and analysed in a metallographic optical microscope (Leica model DM750P).

The tribological tests were performed in triplicate according to the ASTM G99 standard.

The wear rate was determined by equation (1):

$$
K=\frac{m}{l w}
$$

where $K$ is the wear rate $\mathrm{kg}(\mathrm{Nm})^{-1}, m$ the mass lost, $l$ the total sliding distance and $w$ the normal applied load.

\section{Results and discussion}

SEM images of CrAlCN coating are presented in figure 1 . SEM analysis of the coatings revealed dense and very homogeneous coating structures at both front view (figure 1a) and fractured cross-sections (figure $1 \mathrm{~b}-\mathrm{d}$ ). In the cross-section images, uniform thickness is observed and no delamination at the interface of the coating and substrate is evidenced. In figure 1 , a reduction of the film thickness as carbon content increases is evident. Coatings with the lowest carbon
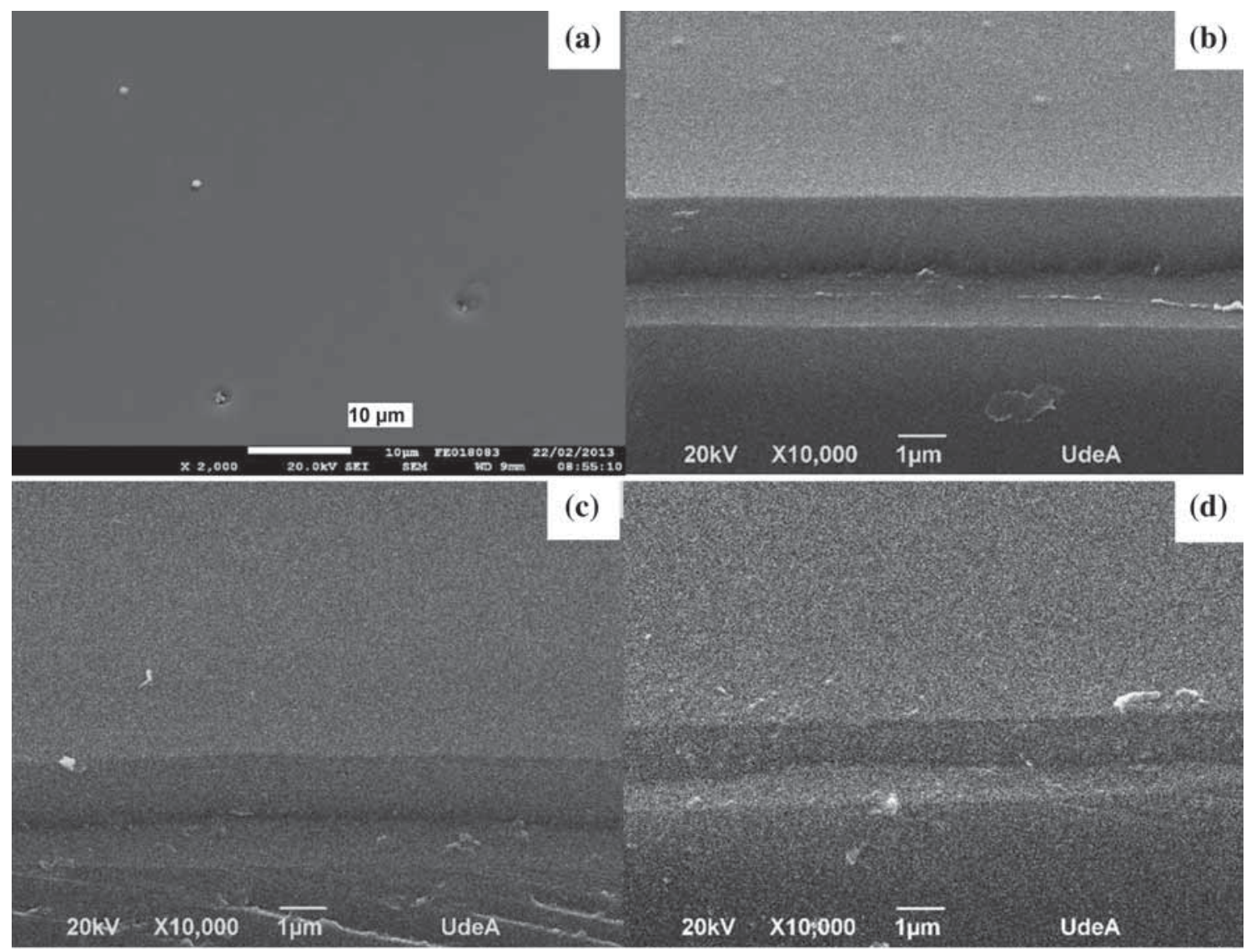

Figure 1. SEM images of deposited coatings of CrAlCN: (a) surface-coating appearance M1, cross-section of the coatings (b) M1, (c) M2 and (d) M5. 
Table 2. Chemical compositions of deposited CrAlCN coatings.

\begin{tabular}{lcrrrrr}
\hline Deposited CrAlCN coatings & $\% \mathrm{CH}_{4} /\left(\mathrm{Ar}+\mathrm{N}_{2}\right)$ & $\mathrm{Cr}(\mathrm{at} \%)$ & $\mathrm{Al}($ at\%) & $\mathrm{C}($ at $\%)$ & $\mathrm{N}($ at $\%)$ & $\mathrm{Cr} / \mathrm{Al}$ ratio \\
\hline $\mathrm{M} 1: \mathrm{Cr}_{1.19} \mathrm{Al}_{1.49} \mathrm{CN}_{6.06}$ & 6.0 & 12.24 & 15.31 & 10.26 & 62.19 & 0.799 \\
$\mathrm{M} 2: \mathrm{CrAl}_{1.37} \mathrm{C}_{2.46} \mathrm{~N}_{6.38}$ & 11.0 & 8.92 & 12.18 & 21.96 & 56.94 & 0.732 \\
$\mathrm{M} 3: \mathrm{CrAl}_{1.35} \mathrm{C}_{6.01} \mathrm{~N}_{7.24}$ & 17.0 & 6.41 & 8.66 & 38.53 & 46.41 & 0.740 \\
$\mathrm{M} 4: \mathrm{CrAl}_{1.57} \mathrm{C}_{15.68} \mathrm{~N}_{10.40}$ & 22.0 & 3.49 & 5.49 & 54.74 & 36.28 & 0.636 \\
$\mathrm{M} 5: \mathrm{CrAl}_{4.68} \mathrm{C}_{171.40} \mathrm{~N}_{35.68}$ & 28.0 & 0.47 & 2.20 & 80.56 & 16.77 & 0.214 \\
\hline
\end{tabular}

content are $\sim 1.5 \mu \mathrm{m}$ thick, while coatings with the higher carbon content are only $1 \mu \mathrm{m}$ thick as determined in triplicate by profilometer measurements (table 2). The explanation for this reduction in the thickness of the coatings is the poisoning of the $\mathrm{Cr} / \mathrm{Al}$ target with carbon and the lower argon ion bombardment due to the reduced argon content in the gas mixture, because Ar is the most responsible for sputtering of the targets. On the other hand, in reactive magnetron sputtering, especially with carbon-rich materials, a phenomenon known as chemical sputtering is carried out. In this process, the energies anchoring the surface species formed between the reactive gases and sputtered atoms are different from the target material, being smaller or larger depending on the nature of the species. Volatile compounds like $\mathrm{CN}^{+}, \mathrm{HCN}^{+}, \mathrm{C}_{2} \mathrm{~N}_{2}^{+}$are potentially formed during the deposition process and these can be desorbed from the surface, resulting in reduced film thicknesses [22]. Consequently, the deposition rate of CrAlCN coatings is also reduced with increasing carbon content in the working gases as shown in table 2. Deposited coatings are free from columnar grains due to the intensive ion bombardment during high bias magnetron sputtering $(-170 \mathrm{~V})$, which caused re-sputtering during the deposition process and prevented the development of columnar morphology. In addition, the progressive formation of carbon-rich amorphous phased product from saturation of the crystalline phase in solid solution contributes to the growth of this type of microstructure [14]. Finally, the grain size of deposited coatings did not show significant changes with increase in the carbon content.

Chemical composition of the deposited coatings determined by EDX is shown in table 2. An increment of carbon content in the coatings accompanied by a reduction in $\mathrm{Cr}, \mathrm{Al}$ and $\mathrm{N}$ is observed as methane gas flow gradually increased. A higher content of $\mathrm{Al}$ with respect to $\mathrm{Cr}$ is also evident, due to the higher sputtering rate of $\mathrm{Al}$. Moreover, the $\mathrm{Cr} / \mathrm{Al}$ ratio decreased compared to the $\mathrm{Cr} / \mathrm{Al}$ ratio of the targets and was further reduced with the increment of methane flow for the different deposition processes, which is consistent with previous research made on TiAlN, CrAlN, TiAlC(N), TiCrAlC(N) and $\operatorname{CrAlC}(\mathrm{N})[18,19,23]$.

In figure 2, XRD phase analysis of the coatings is shown. M1 and M2 coatings with 10.26 and 21.96 at\% carbon, respectively, presented high crystallinity, showing the fcc-CrAlN and $\mathrm{h}-\mathrm{CrN}$, as well c-CrN and $\mathrm{Cr}$-carbide phases, respectively. M1 sample exhibited the most intense peak (112) of

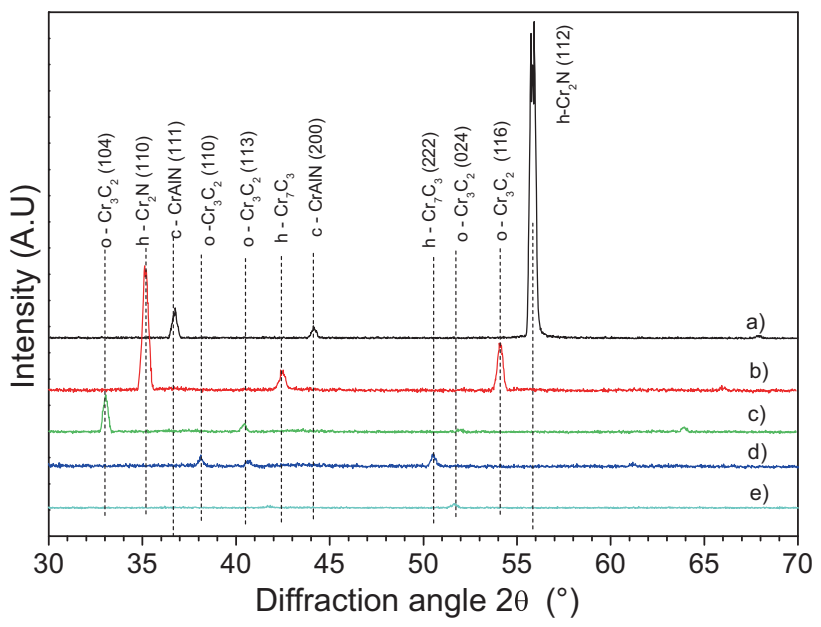

Figure 2. X-ray diffractogram of the CrAlCN coatings: (a) M1, (b) M2, (c) M3, (d) M4 and (e) M5.

the hexagonal $\mathrm{Cr}_{2} \mathrm{~N}$ phase (JCPDS 01-079-2159) followed by CrAlN (JCPDS 01-070-2942) grown in the preferential planes (111) and (200), located at the $2 \theta$ angles $36.6^{\circ}$ and $44.2^{\circ}$, respectively. These peaks correspond to B1-type microstructures of the AlN (JCPDS 01-076-0566) and CrN, respectively, characteristic of the cubic fcc NaCl-type of CrAlN $[24,25]$. This was reported by different authors even at higher percentages of $\mathrm{Al}$ and $\mathrm{Cr}[26,27]$. No carbon compounds were detected for M1 coating with lower carbon content suggesting that the carbon present is in solid solution within the other phases.

M2 sample with 21.96 at\% of carbon exhibited the $\mathrm{Cr}_{2} \mathrm{~N}$ (110) peak with the highest intensity. Additionally, chromium carbide phases $\mathrm{Cr}_{3} \mathrm{C}_{2}$ (JCPDS 03-065-0897) and $\mathrm{Cr}_{7} \mathrm{C}_{3}$ (JCPDS 00-036-1482) formations began to be evident. The formation of these $\mathrm{CrC}$ phases by $\mathrm{M} 2$ sample could probably be attributed to the saturation of the matrix of CrAlN with carbon. At higher percentages of carbon in the coatings, nitrides are not detected and only peaks of chromium carbides, $\mathrm{Cr}_{3} \mathrm{C}_{2}$ and $\mathrm{Cr}_{7} \mathrm{C}_{3}$ are observed. The intensities of these decrease with increased carbon content, suggesting the formation of carbon-rich amorphous phases, as verified and discussed below. For coatings with high carbon content, it is suggested that $\mathrm{CrN}$ and $\mathrm{CrAlN}$ precipitated as nanocrystals in the amorphous-rich carbon matrix and cannot be detected 


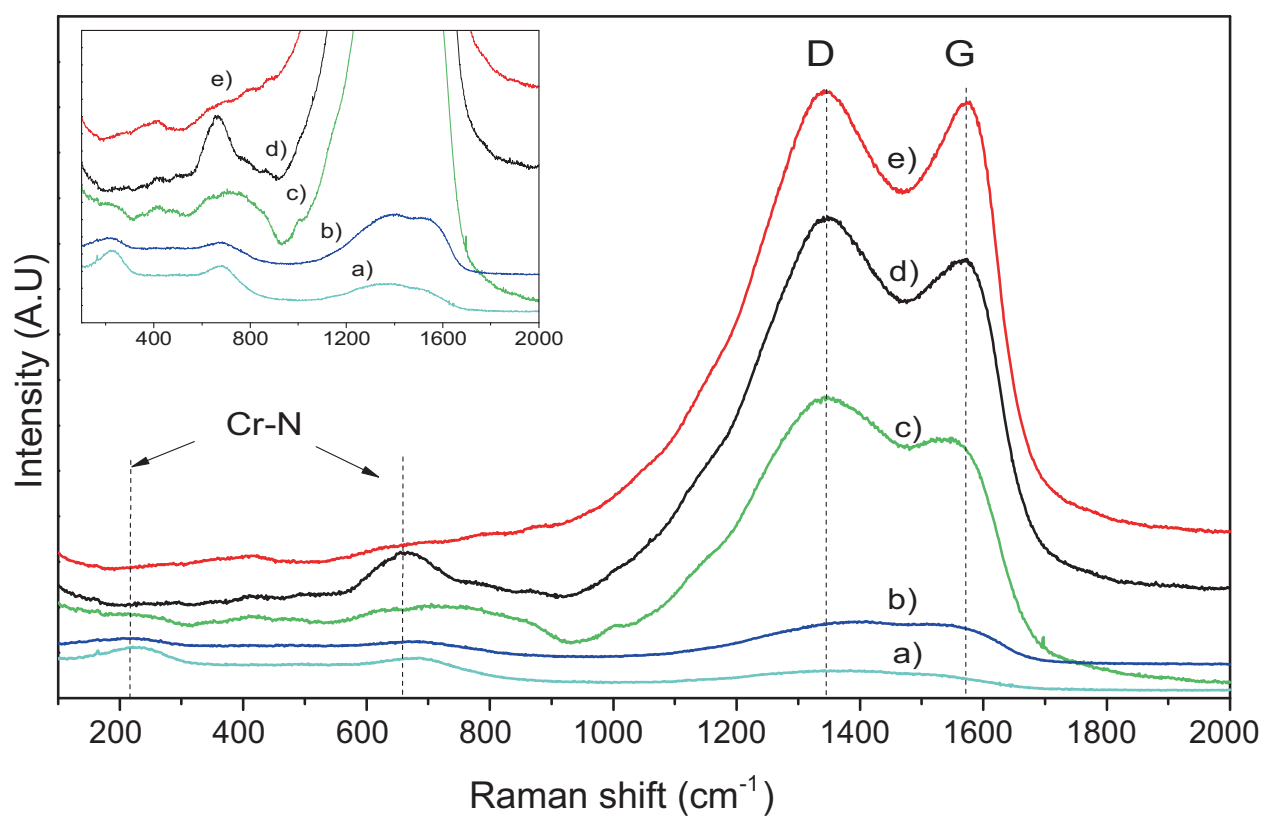

Figure 3. Micro-Raman spectra of CrAlCN coatings: (a) M1, (b) M2, (c) M3, (d) M4 and (e) M5.

by XRD due to their nanometric crystallite size as observed by some authors in other coating systems [23,28].

In figure 3, micro-Raman spectra of CrAlCN coatings, the characteristic vibration of broadbands from $\mathrm{C}-\mathrm{C}$ bond located at 1350 and $1570 \mathrm{~cm}^{-1}$ are seen. These correspond to the amorphous phases present in the coatings and are known, respectively, as D (disorder) and $\mathrm{G}$ (graphite) bands. For the three coatings with higher carbon content, the intensity ratio $\mathrm{D} / \mathrm{G}$ decreases as the carbon content is increased (M3 $=1155$; M4 = 1138; M5 = 1.02), suggesting an increment in the graphite phase. The intensity of the $\mathrm{Cr}-\mathrm{N}$ bands around 220 and $660 \mathrm{~cm}^{-1}$ is lower than the $\mathrm{D}$ and $\mathrm{G}$ bands. This behaviour can be attributed to the metallic character of the $\mathrm{Cr}-\mathrm{N}$ bonds. It is also observed that replacing $\mathrm{Cr}$ atoms with $\mathrm{Al}$ does not affect the Raman spectrum significantly, suggesting that $\mathrm{Al}$ atoms occupy vacancies of $\mathrm{CrN}$ crystal structure. As such, the two bands in the Raman spectrum could be attributed to either CrN or CrAlN. Barshilia et al [10] have reported similar behaviour in ternary nitrides, TiAlN and CrAlN coatings. Wang et al [16] suggest that the predominant structure in this type of coatings is fcc, typical of $\mathrm{CrN}$, and aluminium enters in the system forming solid solutions, which could indicate CrAlN. This could explain the absence of aluminium nitride characteristic bands. Similar behaviours were obtained in the XRD diffractograms (figure 2), where only $\mathrm{CrN}$ and $\mathrm{CrAlN}$ crystalline phases were identified in the M1 coating. This fact revealed the high atomic content of these chemical elements in the microstructure. With increasing methane content, a reduction of the bands centred at 213 and $675 \mathrm{~cm}^{-1}$ corresponding to the $\mathrm{Cr}-\mathrm{N}$ bonds are observed. According to the Raman spectra, it can be concluded that the increment of methane in the working gas mixture and hence, the carbon content in the coatings substantially promotes the formation of D and $\mathrm{G}$ phases. This inhibits the growth of crystalline phases of $\mathrm{CrAlN}$ and $\mathrm{CrN}$, which probably precipitated as nanocrystals in the amorphous-rich carbon matrix and cannot be detected by XRD.

In addition, to provide valuable information about the carbon phases precipitate in the deposited $\mathrm{CrAlCN}$ coatings, a deconvolution of $\mathrm{D}$ (disorder carbon) and $\mathrm{G}$ (graphite-like carbon) bands of the Raman spectra carried out. The tendency of the intensity of the D/G ratio is normally an indicator for the type of carbon that forms within the CrAlCN coatings. Deconvolutions show a decrease in the D/G ratio, suggesting an increase not only in the amorphous carbon phases, but also in particular of the graphite-like $s p^{2}$ bonds, which are known for their self-lubricating effect and are responsible for the reduction of the coefficient of friction of this type of coatings [29].

In figure 4, the hardness and Young's modulus of the CrAlCN coatings are shown. Initially, the hardness and the Young's modulus increase with the carbon content for M1 and M2 samples, probably due to the high content of crystalline phases of $\mathrm{CrN}$ and $\mathrm{CrAlN}$ and to the incorporation of the carbon as a solid solution in the cubic network of CrAlCN. This fact not only generates a deformation of the crystalline lattice, but also represents an obstacle for the displacement of the existing dislocations in the composite coating. However, hardness and Young's modulus are subsequently decreased by increasing the carbon content in the coating due to the continuous formation of a carbon-rich amorphous phase as shown and discussed above in the XRD and Raman evaluation of the coated samples [30-32]. The formation of D and $\mathrm{G}$ amorphous phases of lower hardness results once the 


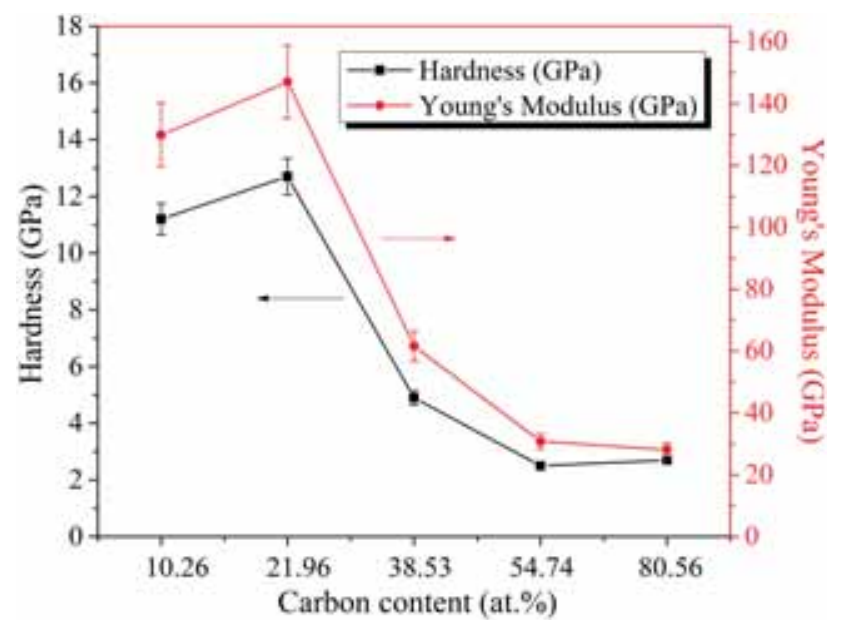

Figure 4. Hardness and Young's modulus of the deposited CrAlCN coatings with different carbon contents.

solubility limit of the carbon in the $\mathrm{CrAlCN}$ was reached, decreasing the hardness of this quaternary alloy, but also the coefficient of friction by the self-lubricating effect of carbon and improving the wear resistance, as discussed below. Similar results were obtained by Choe et al [33] for TiAlCN coatings, which increased their hardness up to $30 \mathrm{GPa}$ for increasing carbon contents up to 20 at $\%$, but to a higher addition of this element, the hardness of the coating was continuously reduced.

The relationship between hardness and Young's modulus, the $H^{3} / E^{2}$ ratio, provides information about the coating's resistance to plastic deformation. The higher this ratio, the greater will be the plastic deformation resistance. The highest value of $H^{3} / E^{2}$ ratio i.e., 0.095 was obtained for the M2 coating with the carbon of 21.96 at\%. This was followed by the M1 sample with a $H^{3} / E^{2}$ ratio of 0.081 , which contained a lower atomic content of carbon with 10.26 at\%. Therefore, it is observed that by increasing the carbon content in the coatings, the $H^{3} / E^{2}$ ratio decreases, presenting its minimum of 0.016 in the M4 coating with a carbon content of 54.74 at $\%$ as shown in table 1 . These results are consistent with the values determined for hardness and Young's modulus of the deposited coatings and are presented in figure 4 .

The behaviour of the friction and wear rate of the samples obtained from ball-on-disk test using $\mathrm{Al}_{2} \mathrm{O}_{3}$ as counterpart material is shown in figure 5. The lowest values of friction were achieved in coatings with 80.56 and 54.74 at $\%$ carbon content, reaching values $<0.20$. Generally, the $\mathrm{COF}$ (friction coefficient) and properties studied in previous sections are highly dependent on the atomic percentage of carbon within the coating. High carbon content leads to amorphous carbon and graphite-like $s p^{2}$ bonds, well-known as a natural solid lubricant, allowing an easy displacement of counterpart material onto the surface of the coating. On the other hand, coatings with low percentages of carbon present higher hardness and average $\mathrm{COF}$ values of 0.5 , which is comparable to the uncoated substrate.

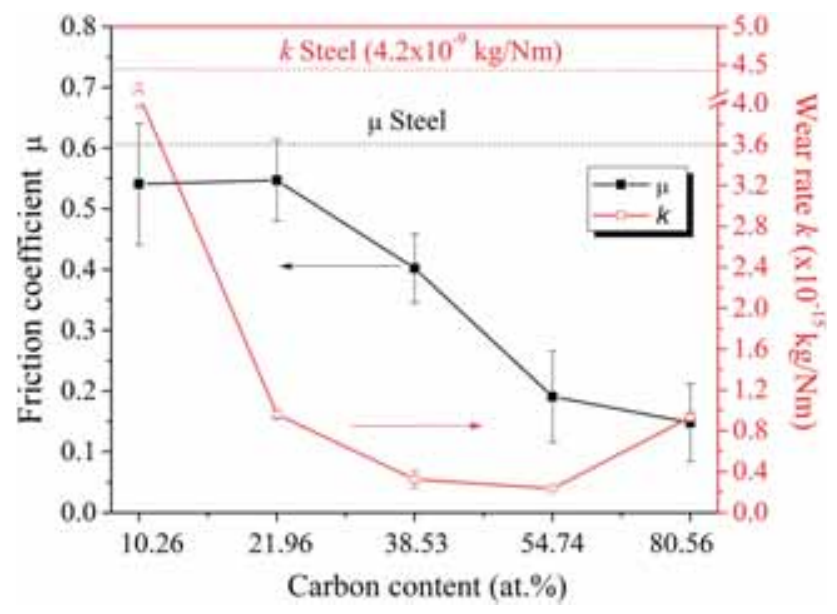

Figure 5. Average coefficients of friction and wear rate of deposited CrAlCN coatings with different carbon contents using $\mathrm{Al}_{2} \mathrm{O}_{3}$ as counterpart material.

In general, $\mathrm{COF}$ and wear rate reduce continuously with increased carbon content in the coatings. The lowest wear rate of $0.32 \times 10^{-15} \mathrm{~kg} \mathrm{Nm}^{-1}$ was obtained by the M4 coating with 54.74 at\% of carbon, which is six times smaller than the uncoated steel sample. This behaviour is associated with the self-lubricating graphite phase, mainly present in coatings with high carbon content.

It is worth highlighting that although M2 sample has presented crystalline structures of nitrides and carbides of chromium, which commonly lead to the generation of high friction coefficients. This coating exhibited a relative low wear rate because of the presence of an adequate contents of $\mathrm{D}$ and $G$ lubricating phases of carbon, accompanied with an appropriate combination of mechanical properties, such as high hardness and Young's modulus. In contrast, although M1 coating presented high crystallinity, it showed low wear resistance. This was possibly due to the fragility of the ceramic coating, probably combined with high residual stress values because of its high thickness in comparison with the other coatings.

Figure 6 shows light microscope images of the wear tracks obtained during ball-on-disk tests using $\mathrm{Al}_{2} \mathrm{O}_{3}$ as counterpart. In figure $6 \mathrm{a}, \mathrm{c}$ and $\mathrm{d}$, tribo-oxidation reaction products are observed in the resultant wear tracks. These products were formed by the interactions between the tribological surfaces and the atmospheric environment. Oxidation of chrome results from the interaction with oxygen in the atmosphere. The relative movement and continuous friction between the surface of the coated sample and the alumina ball under the applied load presented an increase in temperature in the contact area. Additionally, chromium contained in the coatings partially oxidized when it reacted with oxygen in the air. Furthermore, dark wear particles characteristic of the coatings containing carbon were observed inside and around the wear tracks. 


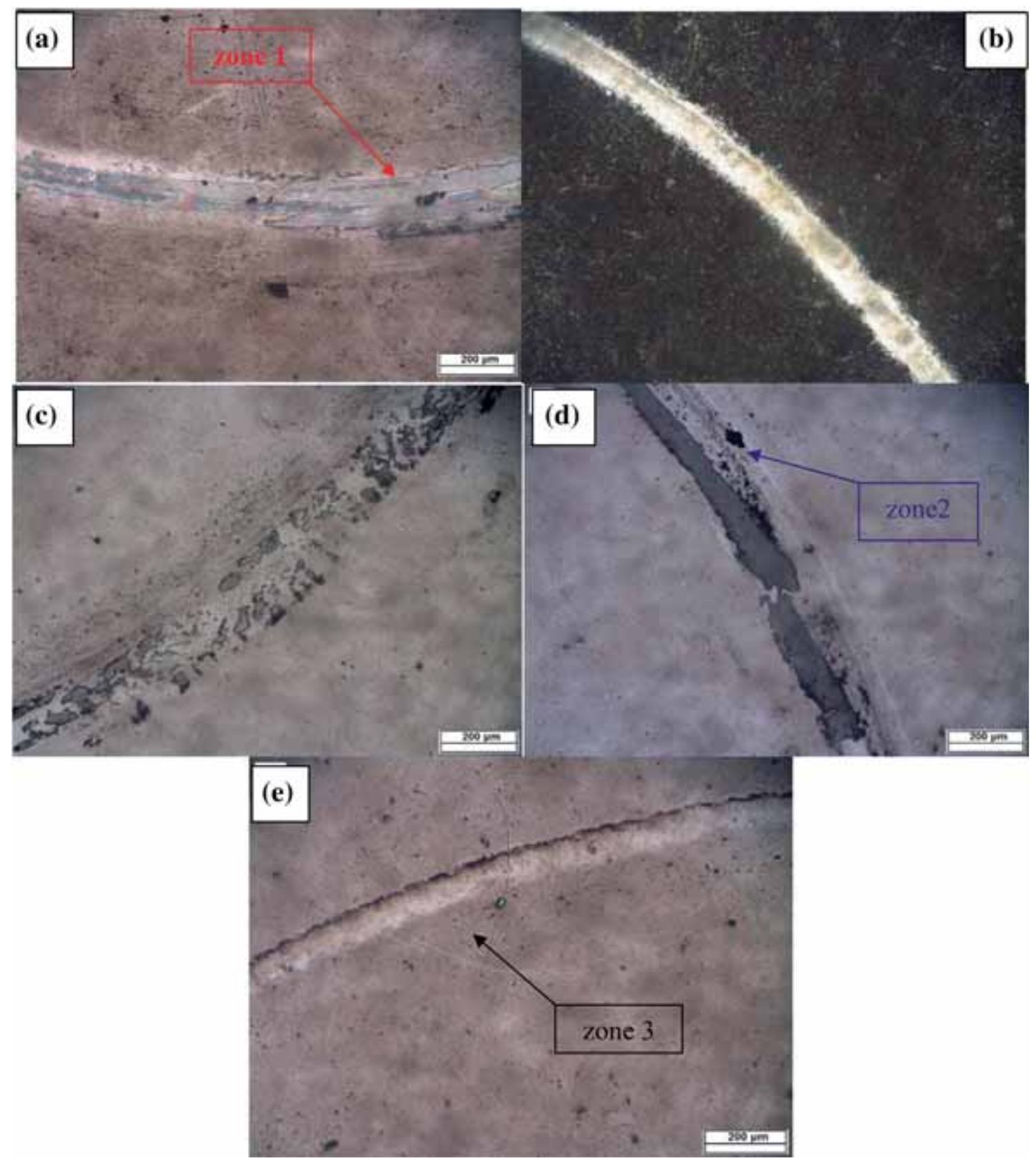

Figure 6. Wear tracks of the deposited CrAlCN coatings after ball-on-disk test with $\mathrm{Al}_{2} \mathrm{O}_{3}$ as counterpart: (a) $\mathrm{M} 1$, (b) M2, (c) M3, (d) M4 and (e) M5.

The M5, which had the highest carbon content (figure 6e), reveals a very smooth wear track. This is a characteristic feature of a surface layer carbon-rich formation, which has a highly lubricating behaviour. Finally, figure 6b corresponding to M2 together with M5 show the lowest width of track. All tribological tests conducted on the coated samples ended without exposing the substrate as evidenced in the images of figure 6 .

To verify the occurrence of tribo-oxidative reactions during the tribological test and the formation of wear particles with high carbon content, micro-Raman analysis of the wear tracks and the obtained debris was conducted in the areas specified in figure 6. Figure 7 shows the micro-Raman spectra obtained from the analysis of the wear tracks. In zones 1 and 2, bands corresponding to $\mathrm{Cr}_{2} \mathrm{O}_{3}$ and $\mathrm{CrO}_{2}$ are identified. Principally, coatings with low carbon and higher chromium contents (see table 2) showed the presence of these oxides. Wide bands of $\mathrm{D}$ and $\mathrm{G}$ carbon-rich phases with very low intensity can be observed for M1 and M3 samples. Therefore, the predominant wear mechanism suggested in these coatings is tribo-oxidation accompanied by adhesive wear along the wear track. In zone 3 of coated M5 sample, the coating shows 


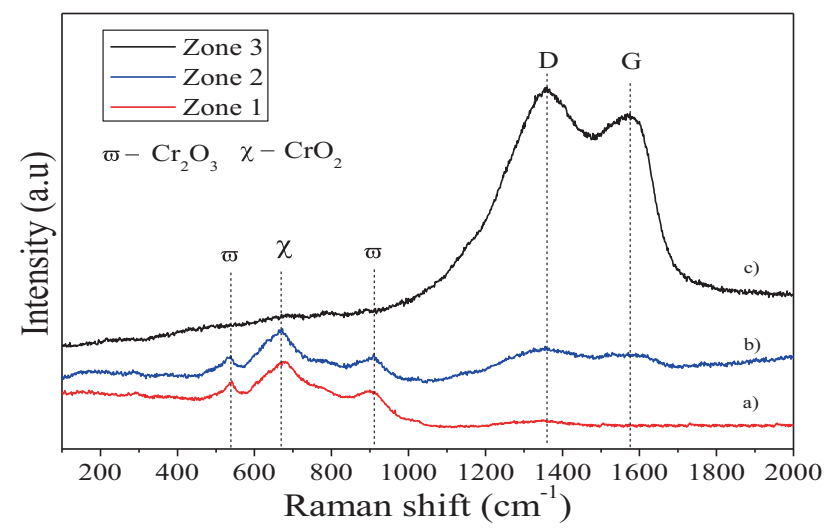

Figure 7. Micro-Raman spectra of selected areas of wear tracks of deposited CrAlCN: (a) M1 zone 1, (b) M3 zone 2 and (c) M5 zone 3.

rich-carbon $\mathrm{D}$ and $\mathrm{G}$ bands with high intensity. The narrow and shallow tracks of this band presented a soft wear without exposure of the substrate. This suggests a mainly adhesive wear due to the solid self-lubricating effect of carbon and graphite, a very important aspect in cutting and shaping tool applications.
Considering the above information, the existence of a transition in the wear mechanisms as the carbon content in the coatings increases, is proposed. At low carbon percentages, chromium oxides are formed as a result of the increment in temperature. At intermediate percentages, the increment of the carbon-rich phases increases the self-lubrication of the coating. This prevents the chromium present in the coating from coming into contact with the oxidizing atmosphere and the rise in temperature at the tribological contact because of the friction. Finally, for coatings with high carbon contents, the phenomenon of self-lubricating due to the presence of phases, such as graphite and amorphous carbon exerts significant protection against wear and oxidation for the substrates.

Rockwell C indentations performed to evaluate the adhesion of the coatings are shown in figure 8, and are classified according to the norm VDI 3198 [34]. The M2 coating does not present cracks or peeling around the indentation mark and is classified in the failure mode HF1. This coating exhibited a good adhesion to the steel substrate. Other coatings were classified as HF3, because microcracks spread in a radial direction were observed. These results are considered as an acceptable failure according to the norm VDI 3198. According to the Rockwell C indent results, all the deposited $\mathrm{CrAlCN}$ coatings presented an acceptable adhesion to the metallic substrate.
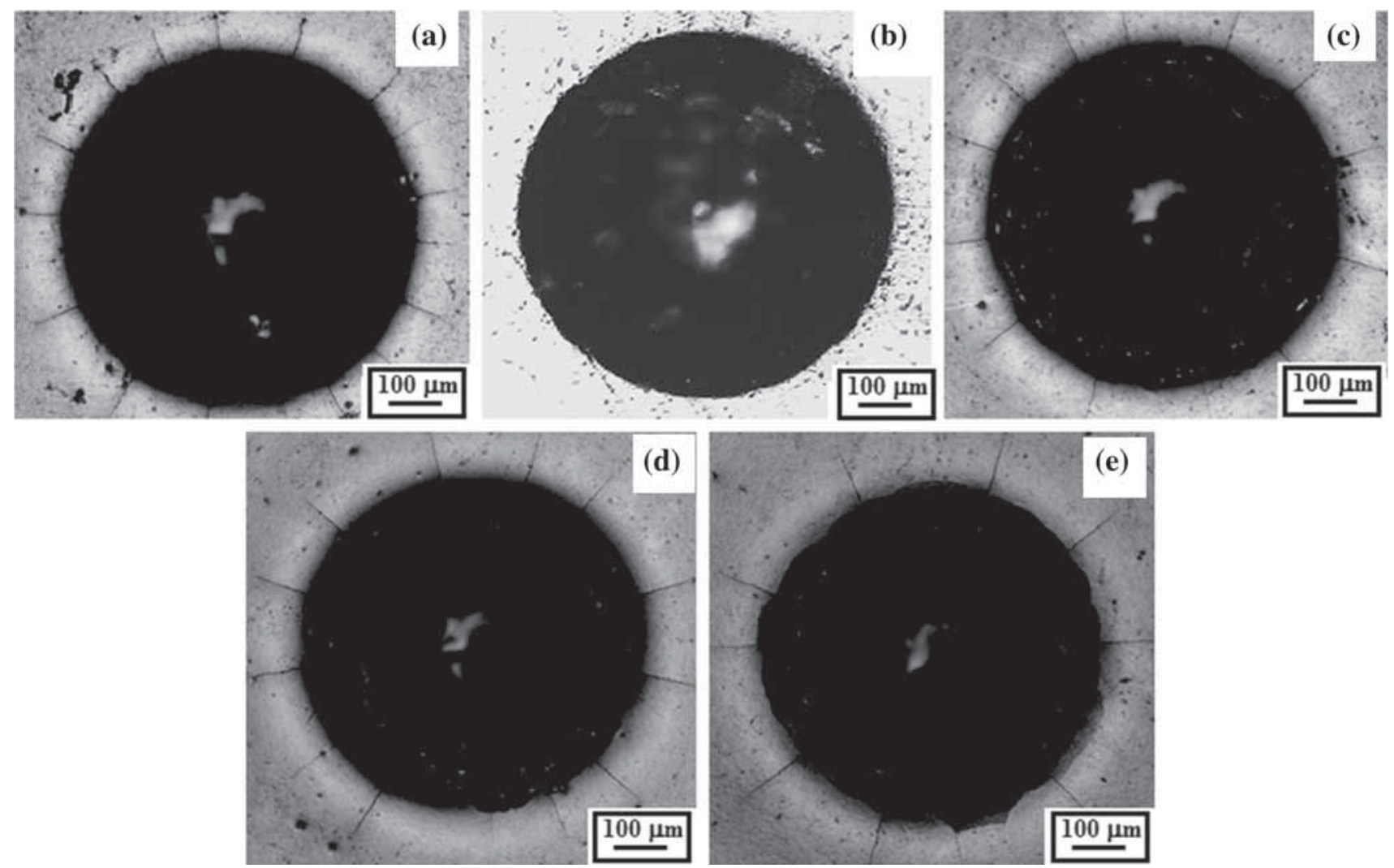

Figure 8. Light microscope images of the Rockwell $\mathrm{C}$ indentations on $\mathrm{CrAlCN}$ coatings deposited with different carbon contents: (a) M1, (b) M2, (c) M3, (d) M4 and (e) M5. 


\section{Conclusions}

CrAlCN coatings with adequate mechanical and tribological properties were successfully deposited on AISI H13 steel samples using the DC unbalanced magnetron-sputtering technique. The carbon content of the coatings could be controlled by varying the flow of methane in the working gas mixture during the deposition process.

The carbon content of the coatings induced changes in the chemical composition, microstructural, mechanical and tribological properties of deposited $\mathrm{CrAlCN}$ coatings. Coatings with lower $\mathrm{C}$ content (10.26 at\%) presented CrAlN cubic phases and $\mathrm{Cr}_{2} \mathrm{~N}$ hexagonal phases. An increased $\mathrm{C}$ content in the coatings promotes the significant reduction of nitrides and the formation of mainly $\mathrm{Cr}_{3} \mathrm{C}_{2}$ and $\mathrm{Cr}_{7} \mathrm{C}_{3}$ carbides in smaller quantities. Carbon content coatings with $>21.96$ at $\%$ mainly presented an increase not only in the formation of amorphous carbon phases, but also, in particular, graphite-like $s p^{2}$ bonds which are known for their self-lubricating effect and are responsible for the reduction of the coefficient of friction of this type of coatings. Except M1 sample, all coatings exhibited D (disorder) and G (graphite) peaks from carbon, whose intensity grew with the increment of $\mathrm{C}$ content in the coatings.

M2 coatings deposited with $\mathrm{CH}_{4} /\left(\mathrm{N}_{2}+\mathrm{Ar}\right)$ ratio of 8/18 and containing 21.96 at\% of carbon, showed the best balance between hardness, Young's modulus, adhesion to the substrate and $H^{3} / E^{2}$ ratio. This balance could be attributed to its high crystallinity and the adequate presence of contents of D and G lubricating phases of carbon conducing to the formation of a nanocomposite coating, constituted of nanocrystals of nitrides and/or carbon nitrides of chromium and aluminium embedded within a graphite-like $s p^{2}$ bonds matrix.

Despite their low hardness, the M4 and M5 coatings with elevated carbon content exhibited the best tribological behaviour due to the high self-lubricating effect of carbon. However, their adhesion to the substrate was not enough and some coatings showed detachment after a few days.

With respect to the wear mechanisms, tribo-oxidation of $\mathrm{Cr}$ occurred mainly in coatings with low carbon content. In coatings with high carbon content, there was a possible formation of a surface layer with rich-carbon amorphous phases in which a solid lubricating effect occurs, leading to a soft adhesive wear.

In accordance with all the results, it is possible to propose the existence of a transition in the wear mechanisms of the $\mathrm{CrAlCN}$ coatings. At low carbon percentages, tribo-oxidative behaviour is shown; chromium oxides as result of the increment of the temperature due to friction. By increasing the carbon content, the coatings principally showed an adhesive wear mechanism due to self-lubricating properties of amorphous carbon during the wear test. For intermediate carbon contents, a combination of tribo-oxidative and adhesive wear mechanisms is suggested.

\section{Acknowledgements}

We are grateful to the Administrative Department of Science, Technology and Innovation-COLCIENCIAS, for the financing of this Project (CT-0005-2012) and also to the University of Antioquia.

\section{References}

[1] Söderberg S 2001 Met. Powder Rep. 5624

[2] Adamiak M and Dobrzan L 2003 J. Mater. Process. Technol. 13350

[3] Chipatecua Y, Marulanda D and Olaya J 2011 Ing. e Investig. 31 16

[4] Gómez M, Lousa A and Esteve J 2010 Rev. Fac. Ing. Univ. Antioquia $\mathbf{5 4} 84$

[5] Beliardouh N, Bouzid K, Nouveaub C and Tlili B 2014 Tribol. Int. 82443

[6] Gómez M, Bejarano G and Osorio J 2010 Rev. Fac. Ing. Univ. Antioquia 5491

[7] Zhou Z, Rainforth W, Rother B and Ehiasarian A 2004 Surf. Coat. Technol. 183275

[8] Rodríguez-Baracaldo R, Benito J, Puchi-Cabrera E and Staia M 2007 Wear 262380

[9] Mayrhofer P and Stoiber M 2007 Surf. Coat. Technol. 2016148

[10] Barshilia H, Selvakumar N, Deepthi B and Rajam K 2007 Surf. Coat. Technol. 2012193

[11] Mo J, Zhu M, Leyland A and Matthews A 2013 Surf. Coat. Technol. 215170

[12] Reiter A, Derflinger V, Hanselmann B, Bachmann T and Sartory B 2005 Surf. Coat. Technol. 2002114

[13] Lin J, Mishra B, Moore J and Sproul W 2008 Surf. Coat. Technol. 2023272

[14] Mayrhofer P, Music D, Reeswinkel T, Fuß H and Schneider J 2008 Acta Mater. 562469

[15] Gómez M, Lousa A and Esteve J 2007 Scientia et Technica. 36 425

[16] Wang L, Zhang G, Wood R, Wang S and Xue Q 2010 Surf. Coat. Technol. 2043517

[17] Yung J, Heo S and Kim K 2008 J. Vac. Sci. Technol. A 26146

[18] Khamseh S, Nose M, Kawabata T, Matsuda K and Ikeno S 2010 J. Alloys Compd. $\mathbf{5 0 3} 389$

[19] Tillmann W, Stangier D and Schröder P 2016 Surf. Coat. Technol. 308147

[20] Endrino J, Palacín S, Aguirre M, Gutiérrez A and Schäfers F 2007 Acta Mater. $\mathbf{5 5} 2129$

[21] Oliver W C and Pharr G M 1995 J. Mater. Res. 383447

[22] Matsuoka M, Isotani S, Mansano R, Sucasaire W, Pinto R, Mittani J et al 2012 World J. Nano Sci. Eng. 292

[23] Lin J, Moore J, Mishra B, Pinkas M and Sproul W 2010 Acta Mater. 581554

[24] Lopez M 2013 Rev. de Fis. 4638

[25] Ruden-Muñoz A, Restrepo-Parra E and Sequeda F 2015 DYNA 82147

[26] Sung K A, Se H K and Kwang H K 2009 J. Korean Phys. 54 1212

[27] Barshilia H and Rajam K S 2004 J. Mater. Res. 193196

[28] Veprek S, Zhang R, Veprek-Heijman M G J, Sheng S H and Argon A S 2010 Surf. Coat. Technol. 2041898 
[29] Wang Z, Li X, Wang X, Cai S, Ke P and Wang A 2016 Surf. Coat. Technol. 304553

[30] Tillmann W, Stangier D, Laemmerhirt I, Biermann D and Freiburg D 2016 Vacuum 1315

[31] Tillmann W, Vogli E, Baumann I and Hoffmann F 2009 Steel Grips 7217
[32] Sheng G, Ji X, Haibo Z, Hao D and Guang X 2016 J. Mat. Eng. 477081

[33] Choe H, Kwon S and Lee J 2013 Surf. Coat. Technol. 228 282

[34] Verein Deutscher Ingenieure Normen 1991 VDI 3198 (Düsseldorf: VDI-Verlag) 